\title{
The perceptions of key stakeholders of the roles of specialist and advanced nursing and midwifery practitioners
}

\author{
Mary Casey \\ University College Dublin, mary.casey@ucd.ie \\ Laserina O'Connor \\ University College Dublin \\ Emma Nicholson \\ University College Dublin
}

See next page for additional authors

Follow this and additional works at: https://arrow.tudublin.ie/tfschhmtart

Part of the Nursing Commons, and the Public Health Commons

\section{Recommended Citation}

Casey, M, O'Connor, L, Nicholson, E, et al. The perceptions of key stakeholders of the roles of specialist and advanced nursing and midwifery practitioners. J Adv Nurs. 2017; 73: 3007- 3016, DOI: 10.1111/ jan.13359

This Article is brought to you for free and open access by the School of Tourism \& Hospitality Management at ARROW@TU Dublin. It has been accepted for inclusion in Articles by an authorized administrator of ARROW@TU Dublin. For more information, please contact arrow.admin@tudublin.ie, aisling.coyne@tudublin.ie, gerard.connolly@tudublin.ie.

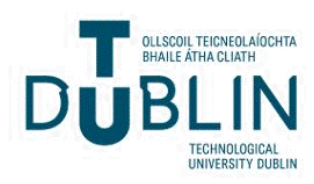




\section{Authors}

Mary Casey, Laserina O'Connor, Emma Nicholson, Rita Smith, Denise O'Brien, Denise O'Leary, Gerard Fealy, Martin McNamara, Diarmuid Stokes, and Claire Egan 


\title{
The perceptions of key stakeholders of the roles of specialist and advanced nursing and midwifery practitioners
}

\author{
Mary Casey $^{1}$ (D) | Laserina O'Connor ${ }^{2}$ | Emma Nicholson ${ }^{2}$ | Rita Smith ${ }^{2}$ | \\ Denise O'Brien $^{2}$ | Denise O'Leary ${ }^{3}$ | Gerard M Fealy ${ }^{2}$ | Martin S Mcnamara ${ }^{2}$ | \\ Diarmuid Stokes $^{4}$ | Claire Egan ${ }^{2}$
}

${ }^{1}$ UCD School of Nursing, Midwifery and Health Systems, University College Dublin, Belfield, Dublin, Ireland

${ }^{2}$ School of Nursing, Midwifery \& Health Systems, University College Dublin, Belfield, Dublin, Ireland

${ }^{3}$ School of Hospitality Management and Tourism, Dublin Institute of Technology, Dublin, Ireland

${ }^{4}$ University College Dublin, Belfield, Dublin, Ireland

\section{Correspondence}

Mary Casey, UCD School of Nursing, Midwifery and Health Systems, University College Dublin, Belfield, Dublin, Ireland.

Email: mary.casey@ucd.ie

Funding information

This research was funded by the

Department of Health, Ireland

\begin{abstract}
Aim: To explore the perceptions of key stakeholders of the roles of specialist and advanced nursing and midwifery practitioners.

Background: There is evidence that the contribution of these roles to patient care is poorly understood.

Design: This research took place over 2 months in 2015 and is part of a larger study involving a rapid review to inform policy development on the specialist and advanced nursing and midwifery practice in Ireland. As an added value, a qualitative element involving thematic analysis was undertaken with key stakeholders.

Methods: A phenomenological qualitative study was conducted incorporating semistructured interviews with key stakeholders $(n=15)$. Purposive sampling with maximum diversity was used to recruit a wide range of perspectives.

Findings: Participant's perspectives led to seven themes: Impact of these roles; role preparation, experience and organizational support; specialist and advanced practice roles in an interdisciplinary context; different folks but not such different roles; impact of specialist and advanced practice roles on patient outcomes; barriers and facilitators to enacting specialist and advanced practice roles; future development of these roles. Conclusion: There is acknowledgement of the positive impact of specialist and advanced practitioners; however, the evidence is currently not conclusive. Preparation for these roles needs to reflect changes in the calibre of today's professional applicants, and organizational support is paramount to their successful execution. The contribution of their activity to patient outcome needs to be made visible to enhance these roles and to justify the development of new roles across a variety of healthcare areas.
\end{abstract}

KEYWORDS

advanced nursing and midwifery practice, qualitative research

\section{1 | INTRODUCTION}

Major challenges for developed countries' health systems in the next decades are the increase in the older population with corresponding increase in chronic conditions, accelerated achievements in technology and information, access and costs of care and the high level of reported inefficiencies of healthcare systems (Flynn, Scott, Rotter, \& Hartfield, 2017). The pressing nature of 
these challenges suggests that changes in the delivery of health care are desirable and inevitable. Interest continues to grow in specialist and advanced practice nursing and midwifery roles as a means of adapting to such changes. However, a key challenge relates to the development of these roles particularly in areas such as the education requirements and the degree of autonomy.

This study addresses the perceptions of key stakeholders of the contribution of specialist and advanced practice nursing and midwifery roles to health care. This is part of a commissioned evidence review using a rapid review (O' Leary et al., 2017) to help shape future national policy development in this area in Ireland. Given the relative paucity of literature on the impact of these roles (Gerrish et al., 2012), the findings could resonate beyond local and national contexts and could be instructive for academic colleagues and professionals based on countries which currently implement or are considering the implementation of these roles.

\section{1 | Background}

Nurse and midwifery specialist (CNS and CMS) and advanced practitioners (ANP and AMP) occupy the most senior clinical roles in the Irish healthcare system. The role has also been adopted by the UK (Gerrish et al., 2012), Italy (Portoghese, Galletta, Battistelli, \& Allegrini, 2012), Australia (Wilkes, Luck, \& O' Baugh, 2015), and Hong Kong (Chan, Sit, \& Lau, 2014). However, the role has not been recognized or implemented internationally with any degree of consistency and the advanced nurse/midwife role is not officially recognized in many European countries including Finland, France, Germany, the Netherlands, Switzerland and Spain (Carney, 2014). Indeed, myriad of terms exist to describe advanced practice roles, and based on a global sample of 30 jurisdictions, Heale and Buckley (2015) identified a general lack of understanding of the advanced practice nursing role and disparities in the advanced practice nursing roles between healthcare settings. Such terms include Nurse Consultant and Nurse Practitioner, Advanced Practice Nurses in the UK and US includes Clinical Nurse Specialists and Advanced Nurse Practitioners (Jokiniemi, Pietila, Kylma, \& Haatainen, 2012; Karnick, 2011), and Australia includes Clinical Nurse Consultants, Clinical Midwifery Consultants (Chiarella, Hardford, \& Lau, 2007; O'Baugh, Wilkes, Vaughan, \& O'Donohue, 2007) and Nurse Practitioners (Gardner, Gardner, \& Proctor, 2004). Confusion also exists with regard to the boundaries of practice, levels of practice, clinical autonomy and preparation for specialist and advanced practice roles (Daly \& Carnwell, 2003; McDonnell, O'Brannagáin, \& McGuigan, 2008). Differences have also been noted in the scope of practice of advanced practitioners, and these differences appear to stem from the varying definitions used across countries, causing confusion among the public and other professions (Cronenwett et al., 2011; Pulcini, Jelic, Gul, \& Loke, 2010). However, it is clear that nurses and midwives are willing to expand their scope of practice to improved patient care,

\section{Why is this research or review needed?}

- There is a general lack of understanding of the advanced practice nursing role and disparities in the advanced practice nursing roles between healthcare settings.

- Preparation, contribution and future development of these roles should be reviewed to ensure that practitioners that are fit for purpose, fit for practice and fit for award.

- The present research aims to explore the perceptions around specialist and advanced nursing and midwifery practitioners from the perspectives of key stakeholders.

\section{What are the key findings?}

- Stakeholder's perceptions of the roles of specialist and advanced nursing and midwifery practitioners reveal a mixed bag of messages; however, there is no doubt about the potential of positive impact of these roles.

- Endorsement of the advanced practice nursing role was considered critical in the context of role preparation, organizational support and interdisciplinary interactions.

\section{How should the findings be used to influence policy/practice/research/education?}

- The contribution of these roles to patient outcome needs to be made visible to enhance these roles and to justify the development of new roles across a variety of healthcare areas.

- Future development of specialist and advanced practice roles is contingent on the extent to which there is empirical evidence to demonstrate role effectiveness in patient and service outcomes.

- An integrated model that can facilitate and guide specialist and advanced practitioners to achieve their capacity will increase the positive outcomes already associated with these roles for patients and for healthcare providers.

quality of standards and increase job satisfaction (Casey et al., 2015).

In Ireland, the core elements of specialist nursing and midwifery practice are clinical focus, advocacy, education and training, audit and research and consultancy (National Council for the Professional Development of Nursing and Midwifery, 2004). The core concepts of the role of advanced practitioner are autonomy, expert practice, professional and clinical leadership, and research (NCNM, 2005). In relation to the latter role, the research element is the least developed (Royal College of Surgeons Ireland, 2010), and recently, Elliott 
et al. (2013) found that the clinical leadership component of the advanced practice role was also underdeveloped. Increasingly, the nursing and midwifery professions in many countries expect preparation of advanced practitioners to be at the master's level, with some recommending education to doctorate level (Draye, Acker, \& Zimmer, 2006; McArthur, 2013). The wide variety in the educational requirements highlights a need for role clarification and suggests that the preparation, contribution and future development of these roles should be reviewed to ensure that practitioners are fit for purpose, fit for practice and fit for award.

\section{2 | THE STUDY}

\subsection{Aim}

To explore key stakeholders' perceptions of the contribution of specialist and advanced practice nursing and midwifery roles to health care. The research question for this study was "What are the perceptions of key stakeholders of the contribution of specialist and advanced practice nursing and midwifery roles to health care?"

\section{2 | Design}

A phenomenological qualitative approach with key stakeholders ( $n=15$ ) was undertaken over 2 months in 2015. Purposive sampling with maximum diversity was used to recruit a wide range of perspectives, and participant recruitment strategies reflected a need for pragmatism given that the commission period for the study was 8 weeks. Data collection involved semi-structured interviews to allow for exploration of the phenomena in question (Parahoo, 2014). Stakeholders were invited to participate by e-mails or phone call and received an information sheet and consent form about the study.

All but one of the interviews were conducted by one member of the research team. Interviews lasted between 30 and 90 min and were audio recorded, with participant consent. A topic guide informed by a preliminary literature review was used for each interview. Questions were open-ended and supported by a series of probes which were used to generate discussion if needed. Every effort was made to undertake the interviews in locations where participants felt comfortable to share their opinions and experiences (Owen, 2001; Stewart, Shamdasani, \& Rook, 2007). The topic guide was subjected to pilot testing initially at the level of the research team, and no modifications were made. The topic guide was used flexibly to "encourage a range of responses (to) provide a greater understanding of the attitudes, behaviour, opinions or perceptions on the... issues" (Hennink, 2007, p.6).

\section{3 | Ethical considerations}

Research Ethics Committee approval was obtained from the Human Research Ethics Committee at University College Dublin. All participants signed a written informed consent form before being interviewed and had the option of withdrawing from the study at any stage. Participants were aware that their participation in this research would have no impact on their roles. Consent was also obtained to audio record the interviews. All data were anonymized and findings reported in a form that ensures anonymity and confidentiality of the participants. Data were retained for 5 years and were kept in an encrypted file on a computer in a locked office, in line with UCD guidelines on data storage.

\subsection{Data analysis}

Interviews were transcribed verbatim and the data uploaded into QSR International's NVivo 11 qualitative data research software to organize data coding and cross referencing. Analysis was guided by the constant comparative technique (Corbin \& Strauss, 2008) which ensured that all data were systematically compared with all other data to enable the recognition of emerging and embedded themes. Thematic analysis (Braun \& Clarke, 2006) was used to make sense of participant accounts. In this way, data from subsequent coding process influenced recoding of the first participants data and the consequent coding of the remaining participants' data (Saldana, 2009). Two members of the research team independently read the transcripts and assigned initial codes inductively through engagement with participant narratives. To ensure consistency, the two researchers analysed the same transcript and agreed a coding framework. The agreed coding framework was used to code the remaining interviews. The initial open codes broke the data down into smaller units of analysis. During axial coding, these codes were collapsed into categories. These categories were compared using selective coding. This process resulted in the clustering and collapsing of codes and the final identification of seven themes.

\section{5 | Rigour and trustworthiness}

Trustworthiness refers to dependability and credibility. Dependability of the interviews was enhanced by the use of a topic guide that was developed based on relevant literature. Dependability was further enhanced by confining the analysis to two members of the research team and seeking consensus and the use of a coding frame that was developed through the data reduction and synthesis process and verified by these members. Credibility was achieved by reading each transcript closely, coding the data into organizing themes where all the data could eventually be accounted for based on similarity of content and substance and thereby providing internal consistency details of "intonation and prosody" were also included (Silverman, 2006, p. 289). In addition, a member check opportunity for participants to read their transcript and the final themes was also provided.

\section{$3 \mid$ FINDINGS}

Most of the participants were over the age of $40 \mathrm{yr}$ and female and all well-educated and in their current roles for more than $1 \mathrm{yr}$ (Table 1). 
As planned, participants were engaged in a range of different roles as highlighted in Table 2 Approximately half of the participants were either specialist nurses or midwives or advanced practitioners. To maintain anonymity of the participants, each participant is identified by a unique code as outlined in Table 2 .

Analysis of participant accounts generated seven themes: impact of these roles; role preparation, experience and organizational support; specialist and advanced practice roles in an interdisciplinary context; different folks but not such different roles; impact of specialist and advanced practice roles on patient outcomes; barriers and facilitators to enacting specialist and advanced practice roles; future development of these roles.

\subsection{Theme 1: Impact of specialist and advanced practice roles}

There was agreement among participants of the value added by these roles as highlighted in the following: "...I would now feel that there is no need to have a doctor in every situation" (MPNRB1). Potential cost saving were highlighted by suggesting a role in the community for advanced nurse practitioners which would: "replace hospital appointments which would free up the hospital resources then, to deal with other issues" (MPNRB1). The education and leadership aspects of these roles were seen as valuable. Providing a supportive role to medical colleagues appears to rest with the practitioners' ability to take on standard cases, leaving more complex cases to medical professions. However, there was a perception that hospital management are not fully aware of the activity of the advanced practitioner:

TABLE 1 Description of Participants

\begin{tabular}{|c|c|}
\hline Demographic data & Number of participants \\
\hline \multicolumn{2}{|l|}{ Age range } \\
\hline $30-34$ & 1 \\
\hline $35-40$ & 0 \\
\hline $41-45$ & 4 \\
\hline $46-50$ & 5 \\
\hline $51-55$ & 5 \\
\hline \multicolumn{2}{|l|}{ Gender } \\
\hline Male & 2 \\
\hline Female & 13 \\
\hline \multicolumn{2}{|l|}{ Highest level of education } \\
\hline Postgraduate diploma & 3 \\
\hline Masters & 10 \\
\hline Doctorate & 2 \\
\hline \multicolumn{2}{|l|}{ Time in current role ${ }^{a}$} \\
\hline Less than $1 \mathrm{yr}$ & 1 \\
\hline $2-5 \mathrm{yr}$ & 7 \\
\hline $6-10 \mathrm{yr}$ & 3 \\
\hline Over $10 \mathrm{yr}$ & 2 \\
\hline
\end{tabular}

${ }^{\text {a }}$ Data related to time in current role is missing for two participants.
TABLE 2 Description of Participants

\begin{tabular}{lcl} 
Titles & $\begin{array}{l}\text { Total } \\
\text { number }\end{array}$ & $\begin{array}{l}\text { Identification in this } \\
\text { report }\end{array}$ \\
$\begin{array}{l}\text { Registered advanced } \\
\text { nurse practitioner } \\
\text { Registered advanced } \\
\text { midwifery practitioner }\end{array}$ & 4 & Identified as AP 1-4 \\
$\begin{array}{l}\text { Clinical nurse specialist } \\
\text { Clinical midwife specialist } \\
\text { Clinical mental health } \\
\text { specialist (Community) }\end{array}$ & 3 & Identified as CS 1-3 \\
\hline $\begin{array}{l}\text { Policy, registration and } \\
\text { management and education }\end{array}$ & 5 & Identified as \\
\hline $\begin{array}{l}\text { Medicine, pharmacy } \\
\text { and nursing } \\
\text { representative body }\end{array}$ & 3 & Identified as \\
\hline \begin{tabular}{l} 
Total \\
\hline
\end{tabular} & & MPNRB1-3 \\
\hline
\end{tabular}

Management ... recognise that we are achieving a lot. They are very positive towards us really and...but I would say they don't really know what we do ...

(AP3)

Additionally, it was noted that: "...putting clinical nurse specialists in place is much more less expensive ... because if you are talking about bed days and $A \& E$ visits, to have someone employed to absolutely give specific clear advice that is going to improve the quality of life for that patient. .." (CS3).

\subsection{Theme 2: Role preparation, experience and organizational support}

The need for greater connection between the education and the clinical sectors "to ensure that the service... meets futuristic requirements ..." (PRME1) was highlighted. However, linking site approval with role approval was not seen as a good option by some participants as seen from the following excerpts:

... So either I'm an ANP or I'm not an ANP... It should not be linked to the place that I'm working. (PRME4)

Another said:

.... So you didn't actually need to regulate an advanced role because like that.., if the [ANP] made an awful faux pas on something ... are you just going to take away the advanced practice piece of regulation or you going to take away all of her nursing ... (PRME1)

The inadequacy of role preparation particularly in relation to research was highlighted by some participants as follows: "...I think ...They learn a lot more about the quality ... of a piece of research when they have to do a piece ... even a small piece of research" (AP1). In terms of prior clinical experience requirement for these roles, there was general agreement that this could be shortened for 
the both roles and particularly for the advanced practice role in recognition of the educational standards of current applicants. Support in the nature of senior management was seen as important to facilitate ongoing development of advanced practitioners as seen in the following excerpt:

...our director of nursing... insisted ...that as part of our contract we have to be supported to attend an international conference every year ... (AP1)

\section{3 | Theme 3: Interdisciplinary interactions}

Participants suggested that interdisciplinary caseload management demands a high level of autonomy and decision-making and a supportive role between nursing and medical colleagues. Organizing clinical meetings is an important aspect of interdisciplinary interactions as seen in the following excerpt:

It's the clinical nurse specialists and the advanced nurse practitioner that ensures this multi-disciplinary team is in place.... They are the linchpin, yeah. That's the word. (PRME2)

A community mental health context indicated that there is ample room for further education on the role of the clinical nurse specialist: "I know that from the MDT (multi-disciplinary team) meeting. They view the role as the jack of all trades..." (CS3). Another participant stated that if her role is not seen to relate directly to medical care, the medical colleagues may not be too interested: "... I do think that it's a valued role among the consultants... but because it's not technically linked to medicine they haven't ever expressed an interest in (CS2)."

There was acknowledgement that greater clarity could be created on the roles of specialist and advanced practitioner as highlighted: "... I don't think the public understand what the role is... and that actually causes a problem ..." (PRME1). This lack of role understanding is common across clinical areas as highlighted by one participant: "Primary care and the public health nurses and the general nurses haven't a clue what we are doing [laughs]" (CS3). Another participant highlighted this same lack of awareness of her role in relation to other disciplines: "Sometimes I think I'm invisible in their eyes. [Laughter]... Seriously..." (AP2).

\subsection{Theme 4: Different folks but not so different roles}

Several participants highlighted that there is clearly some contention about difference between specialist and advanced practice as highlighted in the following:

I think some nurses don't agree with the role. They don't see that there needs to be a difference between ... my role in the unit and their role...They don't see that the advanced practice role is supposed to have a different element and a different level of care. (AP1)

Some participants feared that specialization can lead to underuse and deskilling and that nurses and midwifes can find themselves in situations where they feel that they are working outside their scope of practice as seen in the following excerpt:

...there was a big car crash recently ... she ran in to get her ANP and said can you come and give us a hand in resus [resuscitation room]; [She answered referring to the ANP] 'I'm not competent'... So there was complete de-skilling. ...(PRME1)

Role differentiation is clarified somewhat in terms of higher order of tasks as seen in the following excerpt:

The difference in our role is that we can make diagnosis

... The clinical nurse specialist ... don't make diagnosis.

... I would think at an advanced practice level you have more of a leadership role... (AP1)

The role boundary between specialist and advanced roles has also become blurred and the need for both a specialist and advanced roles is not always clear:

...I don't know whether or not do we need both roles, the clinical nurse specialist and the advanced role and in the context of ...our four year degree with all the education people are receiving, I am not sure whether... we should keep with the two roles. ... (MPNRB3)

\section{5 | Theme 5: Impact of specialist and advanced practice roles on patient outcomes}

The impact of specialist and advanced roles was highlighted as difficult to measure as the clinical aspects of the roles took precedence. However, where evaluation did occur albeit informally, it highlighted the positive impact on patient outcomes as seen in the following excerpt:

...when there's an ANP on they are seen much quicker, much more efficiently by somebody actually who knows what they are doing. They are not seen by somebody junior [referring to junior doctors] who escalates it up ... (AP2)

Consistency in care was a feature of specialist and advanced practice services as patients and clients usually received care from the same nurse or midwife as seen in the following excerpt: 
...one of the biggest advantages has been the consistency in care that's having an advanced practitioner ...Advanced nurse practitioners available in the unit at all times to support the NCHDs (non-consultant hospital doctor) ... (AP1)

Access to care via advanced practice service seemed positive and reduced costs by freeing up hospital resources, as in all cases, the advanced practice service is free of change "No ... there's no charge. Whereas if you go into A\&E they have $€ 100$ euros" (AP2). However, this has to be taken in the light of case load management where specialist and advanced practitioners seem to have to add the "unplanned" cases to their existing caseload as highlighted in the following account:

...we would have to slot them in on top of an already hectic day. But we have to do that because ... if a patient is having a lot of problems... they will end up coming into casualty so we are trying to avoid that. . we would never turn them away. ... (CS1)

\section{6 | Theme 6: Barriers and facilitators to developing specialist and advanced practice roles}

Organizational support as embodied by a director of nursing was seen as an enabler of the role. Some barriers to the roles related to structures in the institution, either procedural, the bureaucracy, or physical as highlighted in the following quote:

...we don't necessarily have the geography or the space or a room or time, actual clinic time to give another [advanced practitioner], that is actually a problem... So it is not just about them not wanting it,.... It is an obstacle (AP4)

Some participants reported that multidisciplinary team members were supportive of their role. Others highlighted an alternative view as highlighted in the following excerpt:

There was some barriers certainly from the medical side of things where the physicians felt like [advanced nurse practitioners] were encroaching on their territory (PRME5)

A poor relationship with other nurses and other professionals was seen to be problematic as it created unnecessary barriers for nurses and midwives working in specialist and advanced practitioner posts:

...we have a load of nurses who won't take referrals from nurses or clinical nurse specialists or advanced nurse practitioners. We have other members of the healthcare team who will only take referral once it comes through various other members of the medical team... (PRME1)

Many of the ANP s were working as lone practitioners and having at least one colleague in a similar role was seen as enabling: "... so when I am on annual leave I have to really cleverly diary manage. . .here is a deficit" (AP4). Another participant stated "It's a huge advantage to have somebody else that you can run ideas off and come up with ideas and discuss things" (AP3). Most participants highlighted the need for more of these roles, but suggested that there are regulatory and credentialing-related barriers in place which are making it difficult to increase the numbers.

\section{7 | Theme 7: Future development of specialist and advanced practice roles}

There was general agreement that specialist and advanced practitioner roles could be expanded to the community, primary care and private sectors. Participants highlighted that a clear and structured career pathway is needed and that individual career pathways must take client and patient needs into account as follows:

So it's about developing people's career pathways and allowing them develop within them. And making them flexible ... Absolutely, an enabling framework that each kid who finishes the programme can see themselves popping on and popping off this particular pathway.(PRME1)

Participants also highlighted that nurses and midwives who have been in specialist and advanced positions for several years have the potential to support and supervise others in training for these roles. Participants views on the future preparation for the roles include topics such as: ". . . self-development, self-awareness, developing emotional intelligence, how to network, how to present yourself, how to speak. That is part of preparation for advanced practice" (AP4). Several participants talked about a more generic approach to advanced practice. This view is highlighted in the following statement:

...I think in education if you can give them the principles, if you can give them the generic principles, concepts and understanding... It is a bit like when I talk about prescribing... So it is about ensuring that they have skills and abilities that they are able to evolve into a particular role and not pigeonhole them ... (MPNRB3)

Some discussion on continued competency involved a re-credentialing process perhaps every five years - with practitioners maintaining a portfolio of evidence: "...there needs to be some sort of mechanism of how we can actually recognize or put a quality stamp on some of these education bites because..." So that people are developing these baskets of learning and baskets of skill sets that 
are unique to them and that's great to be able to do that but to streamline and make that easy for people ...(PRME1)

\section{DISCUSSION}

In relation to the impact of these roles, there is empirical evidence that expanding practice through clinical specialist and advanced practice roles has demonstrable clinical and practitioner benefits (Gerrish, McDonnell, \& Kennedy, 2013). The SCAPE study (Begley et al., 2010) demonstrated conclusively that the care provided by CNS/ CMS/ANP/AMP improved patient/client outcomes and was safe, acceptable and cost-neutral. Six domains of practice were identified in the SCAPE study (Begley et al., 2010) as important for evaluation: (i) communication with the clinician, (ii) waiting times, (iii) service user confidence in the clinician and the process, (iv) service user level of satisfaction, ( $v$ ) service user demographic profile, and finally, (vi) the service users' overall impression of the care they received. Indicators for each of these areas could be used for future measurement of the impact of these roles.

In the context of role preparation, organizational support and interdisciplinary interactions, the process of endorsement is essential. This generally involves establishing agreed practice standards by a regulatory authority, the provision of accredited education and training programmes, and the accreditation and/or registration of the individual practitioner and/or the place of practice. Critical to endorsement is the need to achieve definitional clarity (Cashin et al., 2015). Endorsement for the roles must be supported by service providers and employers, and this generally requires endorsement from the medical profession (Heale \& Buckley, 2015). However, the medical profession continues to seek to control nursing practice through retention of physician-led healthcare teams and clinical jurisdiction (Nardi, 2014). This lack of professional jurisdiction over its own practice is compounded by a lack of strategic leadership in government and nursing organizations for the role (Heale \& Buckley, 2015). A key enabler for these roles is support from others, and this is supported in the literature particularly from work colleagues and from service managers (Casey et al., 2015). Administrative support was also found to be a key to the success of these roles (Campbell \& Profetto-McGrath, 2013; Poghosyan et al., 2013).

In relation to confusion between specialist and advanced practitioner role boundaries, Carney (2014) also found that the variance in titles and levels of education being used to designate the advanced nurse practitioner are contributing to the lack of official recognition of the role and is having an adverse impact on the professional role. The importance of credentialing through various mechanism that include registration legislation and professional regulation, licensure and certification, accrediting educational programmes, practice experience and titling (Nardi, 2014) facilitates a better understanding of the role. The presence of a framework to guide the development and accreditation of specialist and advanced practitioner roles also facilitates the fuller expression of the leadership dimension of the role (Higgins et al., 2015). Regulation was mentioned as important by some participants while others stated that the current requirement for site approval was no longer a viable option. In a similar vein, Heale and Buckley (2015) examined the status of regulation for advanced practice nursing in 30 countries, the authors identified the existence of credentialing criteria, such as licensure or mandatory educational programmes and reported that the factors that prevented the APNs from practising to full scope were legislative limitations and a lack of regulation of the role, lack of title protection and low nursing representation in policy development.

Interdisciplinary interactions were valued though ample room for improvement was evident particularly in relation to public awareness of the specificity of different roles. This lack of definitional clarity can give rise to confusion for other health professionals who may be uncertain as to the extent of the advanced practitioner's expertise, for patients who may not know when to consult an advanced practice nurse and for academic institutions designing and marketing degrees (Stasa, Cashin, Buckley, \& Donoghue, 2014). This also relates to internal understanding of these roles among the individual and the professions in that there may be different individuals with different qualifications providing the same level of expert care. Ways of overcoming role ambiguity include practitioners themselves clearly articulating their roles, either verbally in context or through detailed job descriptions (Foster \& Flanders, 2014). Gerrish et al. (2013) suggest that future research should aim to capture the actual impact of these roles on practice, and they conclude that nurse consultants must also identify areas of impact in their own practice.

In relation to the impact of these roles on patient outcomes, actual measurement of impact has been difficult to measure statistically (Kennedy et al., 2012). The nurse practitioners (NP) role is seen as a viable alternative to physicians when it comes to dealing with the growing cost of health care, since NPs are seen as having a distinct role in filling the gap left by finite resources and can provide cost effective, high-quality care (Archibald \& Fraser, 2013). Gerrish et al. (2013) developed a framework to evaluate the impact of nurse consultants (NCs) on patient, professional and organizational outcomes and identify associated indicators of impact in the National Health Service (NHS) across the UK. The study found that the Schulz et al. (2002) framework has the potential to help nurse consultants to identify areas of impact in their own practice.

Enablers and barriers to these roles related to wide range of issues not lest role ambiguity but also to the lack of, time, collegial and organizational support and workload. Reference was also made to the lack of physical work space, and this is similar to findings of McKenna, Halcomb, Lane, Zwar, and Russell's (2015) on the lack of management support in practices to support nurse roles and time constraints that curtailed nurses in their ability to participate in advanced care activities, while having a distinct nursing workspace to practise in the general practice setting.

The final theme relates to the future development of these roles. In general, there was explicit support for these roles but without strong objective evidence. Franks and Howarth (2012) also identified a lack of evidence to support the value of the nurse consultant (NC) role in the UK which was seen as a threat to the role 
development. Clinical leadership and research activities are key requirements for this role (Franks \& Howarth, 2012; Elliott et al., 2013). Ideas for curriculum for future educational programmes content were put forward by participants, and these included selfdevelopment, self-awareness, networking and public speaking, which are all associated with clinical leadership development (Casey, McNamara, Fealy, \& Geraghty, 2011). In addition, the need to capture professional learning in a portfolio relates to professional competence where a self-reflective, professional portfolio was seen as a way to demonstrate evidence of continuing competency and ensuring quality patient care (Casey et al., 2017). Future development of these roles needs a pathway to enable nurses and midwives to see direction, there was also an expressed need for a more generic approach to the educational pathway in terms of a principle-based approach, and finally, more research is needed to measure the impact of these roles. This relates with the need for future research to "identify the distinct focus of advanced practice and to explain the complexity of specialist interventions" (Begley et al., 2010: 6).

\subsection{Limitations}

The sample size and that majority of participants were specialist and advanced nurse and midwifery practitioners regional focus impose limitations on the strength of claims we can make. In addition, there emerged a focus on nurses and midwives employed in larger hospitals where practice development is an expectation, and there is availability of appropriate supports, including the provision of continuing education albeit, subject to current resource constraints. There is less consideration of the needs of nurses working in remote areas, smaller community settings and non-teaching hospitals; hence, the experience of specialist and advanced practitioners may be somewhat different. Moreover, the exclusion of patients' perceptions further limits the findings of this research.

\section{CONCLUSION}

Stakeholder's perceptions of the roles of specialist and advanced nursing and midwifery practitioners reveal a mixed bag of messages; however, there is no doubt about the potential of positive impact of these roles. However, factual evidence supporting the positive impact of these roles is urgently needed. Developing a cadre of specialist and advanced nurse and midwife practitioners offers the potential to improve access to care, improve quality and reduce expenditure on health services, where otherwise the services are provided by physicians and surgeons, who traditionally command a higher salary.

Future development of specialist and advanced practice roles is contingent, in part, on the extent to which there is empirical evidence to demonstrate role effectiveness in patient and service outcomes and much of this evidence comes from practitioner-generated outcomes data. An integrated model that can facilitate and guide specialist and advanced practitioners to achieve their capacity will increase the positive outcomes already associated with these roles for patients and for healthcare providers.

\section{CONFLICT OF INTEREST}

There are no conflicts of interest to be declared by the authors.

\section{AUTHOR CONTRIBUTIONS}

All authors have agreed on the final version and meet at least one of the following criteria [recommended by the ICMJE (http://www.ic mje.org/recommendations/)]:

- substantial contributions to conception and design, acquisition of data, or analysis and interpretation of data;

- drafting the article or revising it critically for important intellectual content.

\section{REFERENCES}

Archibald, M. M., \& Fraser, K. (2013). The potential for nurse practitioners in health care reform. Journal of Professional Nursing, 29, 270-275.

Begley, C., Murphy, K., Higgins, A., Elliott, N., Lalor, J., Sheerin, F., ... SCAPE) (2010). Evaluation of clincial nurse and midwife specialist and advanced nurse and midwife practitioner roles in ireland (SCAPE) report Dublin: National Council for the Professional Development of Nursing and Midwifery in Ireland.

Braun, V., \& Clarke, V. (2006). Using thematic analysis in psychology. Qualitative Research in Psychology, 3(2), 77-101.

Campbell, T. D., \& Profetto-McGrath, J. (2013). Skills and attributes required by clinical nurse specialists to promote evidence-based practice. Clinical Nurse Specialist, 27(5), 245-254.

Carney, M. (2014). International perspectives on Advanced Nurse and Midwife Practice, regarding advanced practice, criteria for posts and persons and requirements for regulation of Advanced Nurse/Midwife Practice. Nursing and Midwifery Board of Ireland (An Bord Altranais agus Cnáimhseachais na hÉireann), Dublin, Ireland.

Casey, M., Cooney, A., O'Connell, R., Hegarty, J., Brady, A. M., Kennedy, C. M., ... O'Connor, L. (2017). Nurses, midwives and key stakeholders experiences and perceptions on requirements to demonstrate the maintenance of professional competence: An Irish Study. Journal of Advanced Nursing, 73(3), 653-664.

Casey, M., Fealy, G., Kennedy, C., Hegarty, J., Prizeman, G., McNamara, M., ... Rodhe, D. (2015). Nurses', midwives' and key stakeholders' experiences and perceptions of a scope of nursing and midwifery practice framework. Journal of Advanced Nursing, 71(6), 1227-1237.

Casey, M., McNamara, M., Fealy, G., \& Geraghty, R. (2011). Nurses' and midwives' clinical leadership development needs: A mixed methods study. Journal of Advanced Nursing, 67(7), 1502-1513.

Cashin, A., Buckley, T., Donoghue, J., Heartfield, M., Bryce, J., Cox, D., ... Dunn, S. V. (2015). Development of the nurse practitioner standards for practice australia. Policy, Politics and Nursing Practice, 16(1), 27-37.

Chan, J. C. Y., Sit, E. N. M., \& Lau, W. M. (2014). Conflict management styles, emotional intelligence and implicit theories of personality of nursing students: A cross-sectional study. Nurse Education Today, 34(6), 934-939.

Chiarella, M., Hardford, E., \& Lau, C. (2007). Report on the evaluation of nurse/midwife practitioner and clinical nurse/midwife consultant roles. Sydney: NSW Department of Health.

Corbin, J., \& Strauss, A. (2008). Basics of qualitative research: Techniques and procedures for developing grounded theory. (3rd ed.). Thousand Oaks, CA: Sage. 
Cronenwett, L., Dracup, K., Grey, M., McCauley, L., Meleis, A., \& Salmon, M. (2011). The doctor of nursing practice: A national workforce perspective. Nursing Outlook, 59(1), 9-17.

Daly, W., \& Carnwell, R. (2003). Nursing roles and levels of practice: A framework for differentiating between elementary, specialist and advanced nursing practice. Journal of Clinical Nursing, 12(2), 158-167.

Draye, M. A., Acker, M., \& Zimmer, P. A. (2006). The practice doctorate in nursing: Approaches to transform nurse practitioner education and practice. Nursing Outlook, 54(3), 123-129.

Elliott, N., Higgins, A., Begley, C., Lalor, J., Sheerin, F., Coyne, I., \& Murphy, K. (2013). The identification of clinical and professional leadership activities of advanced practitioners: Findings from the specialist clinical and advanced practitioner evaluation study in Ireland. Journal of Advanced Nursing, 69(5), 1037-1050.

Flynn, R., Scott, S., Rotter, T., \& Hartfield, D. (2017). The potential for nurses to contribute to and lead improvement science in health care. Journal of Advanced Nursing, 73(1), 97-107.

Foster, J., \& Flanders, S. (2014). Challenges in clinical nurse specialist education and practice. Online Journal of Issues in Nursing, 19(2), 10913734

Franks, H., \& Howarth, M. (2012). Being an effective nurse consultant in the English National Health Service: What does it take? A study of consultants specializing in safeguarding Journal of Nursing Management, 20, 847-857.

Gardner, G., Gardner, A., \& Proctor, M. (2004). Nurse practitioner education: A research-based curriculum structure. Journal of Advanced Nursing, 47(2), 143-152.

Gerrish, K., McDonnell, A., \& Kennedy, F. (2013). The development of a framework for evaluating the impact of nurse consultant roles in the UK. Journal of Advanced Nursing, 69(10), 2295-2308.

Gerrish, K., Nolan, M., McDonnell, A., Tod, A., Kirshbaum, M., \& Guillaume, L. (2012). Factors influencing advanced practice nurses' ability to promote evidence-based practice among frontline nurses worldviews evidence based. Nursing, 9(1), 30-39.

Heale, R., \& Buckley, R. (2015). An international perspective of advanced practice nursing regulation. International Nursing Review, 62(3), 421429.

Hennink, M. M. (2007). International focus group research: A handbook for the health and social sciences. Cambridge: Cambridge University Press.

Higgins, A., Begley, C., Lalor, J., Coyne, I., Murphy, K., \& Elliott, N. (2015). Factors influencing advanced practitioners' ability to enact leadership: A case study within Irish healthcare. Journal of Nursing Management, 22, 894-905.

Jokiniemi, K., Pietila, A.-M., Kylma, J., \& Haatainen, K. (2012). Advanced nursing roles: A systematic review. Nursing \& Health Sciences, 14, 421-431.

Karnick, P. M. (2011). Theory and advanced practice nursing. Nursing Science Quarterly, 24(2), 118-119.

Kennedy, F., McDonnell, A., Gerrish, K., Howarth, A., Pollard, C., \& Redman, J. (2012). Evaluation of the impact of nurse consultant roles in the United Kingdom: A mixed method systematic literature review. Journal of Advanced Nursing, 68(4), 721-742.

McArthur, D. B. (2013). The journey to the doctor of nursing practice degree. In K. Moran, R. Burson \& D. Conrad (Eds.), The doctor of nursing practice scholarly project.(pp. 287-297). Burlington, MA: Jones \& Bartlett Learning.

McDonnell, M., O'Brannagáin, D., \& McGuigan, E. (2008). Development of Advanced Nurse Practitioner model for specialist pallative care HSE Dublin North-East for the three local health offices of Louth, Meath, Cavan/Monaghan and hospital network 3. Ireland: Health service Executive North East: Drogheda.

McKenna, L., Halcomb, E., Lane, R., Zwar, N., \& Russell, G. (2015). An investigation of barriers and enablers to advanced nursing roles in Australian general practice. Collegian, 22, 183-189.
Nardi, D. A. (2014). Global trends and issues in APN practice: Engage in the change. Professional Nursing, 30(3), 228-232.

National Council for the Professional Development of Nursing and Midwifery. (2004). Framework for the establishment of clinical nurse/midwife specialist posts (2nd ed). Dublin: NCNM.

National Council for the Professional Development of Nursing and Midwifery (NCNM). (2005). An evaluation of the effectiveness of the role of the advanced nurse practitioner (2nd ed). Dublin: NCNM.

O' Leary, D., Casey, M., O' Connor, L., Stokes, D., Fealy, G., O' Brien, D., Smith, R., McNamara, M., \& Egan, C. (2017). Using rapid reviews in nursing and midwifery research: An example from a study commissioned to inform policy-making. Journal of Advanced Nursing, 10, 03:10PM EST | https://doi.org/10.1111/jan.13231

O'Baugh, J., Wilkes, L. M., Vaughan, K., \& O'Donohue, R. (2007). The role and scope of the clinical nurse consultant in Wentworth area health service, New South Wales, Australia. Journal of Nursing Management, 15(1), 12-21.

Owen, S. (2001). The practical, methodological and ethical dilemmas of conducting focus groups with vulnerable clients. Journal of Advanced Nursing, 36(5), 652-658.

Parahoo, K. (2014). Nursing research: Principles, process and issues (3rd ed.). Basingstoke: Palgrave Macmillan.

Poghosyan, L., Nannini, A., Smaldone, A., Clarke, S., O'Rourke, N. C., Rosato., B. G., \& Berkowitz, B. (2013). Revisiting scope of practice facilitators and barriers for primary care nurse practitioners: A qualitative investigation. Policy, Politics, \& Nursing Practice, 14, (1), 6-15.

Portoghese, I., Galletta, M., Battistelli, A., \& Allegrini, E. (2012). Changerelated expectations and commitment to change of nurses: The role of leadership and communication. Journal of Nursing Management, 20 (5), 582-591.

Pulcini, J., Jelic, M., Gul, R., \& Loke, A. Y. (2010). An International survey on advanced nursing practice, nursing education, practice and regulation. Journal of Nursing Scholarship, 42(1), 31-39.

Royal College of Surgeons Ireland (2010). Evaluation of the role of the clinical nurse specialist in cancer care report. Dublin: RCSI.

Saldana, J. (2009). The coding manual for qualitaitve researchers. London: Sage.

Silverman, D. (Ed.) (2006). Qualitative research: Theory method and practice. London: Sage.

Stasa, H., Cashin, A., Buckley, T., \& Donoghue, J. (2014). Advancing advanced practice: Clarifying the conceptual confusion. Nurse Education Today, 34(2), 356-361.

Stewart, D. W., Shamdasani, P. N., \& Rook, D. W. (2007). Focus groups: Theory and practice (2nd ed.). Thousand Oaks, CA: Sage.

Wilkes, L., Luck, L., \& O' Baugh, J. (2015). The role of a clinical nurse consultant in an Australian health district: A quantitative survey. BMC Nursing, 14(25), https://doi.org/10.1186/s12912-015-0075-9

\section{SUPPORTING INFORMATION}

Additional Supporting Information may be found online in the supporting information tab for this article.

How to cite this article: Casey M, O'Connor L, Nicholson E, et al. The perceptions of key stakeholders of the roles of specialist and advanced nursing and midwifery practitioners. J Adv Nurs. 2017;73:3007-3016. https://doi.org/ 10.1111/jan.13359 
The Journal of Advanced Nursing (JAN) is an international, peer-reviewed, scientific journal. JAN contributes to the advancement of evidencebased nursing, midwifery and health care by disseminating high quality research and scholarship of contemporary relevance and with potential to advance knowledge for practice, education, management or policy. JAN publishes research reviews, original research reports and methodological and theoretical papers.

For further information, please visit JAN on the Wiley Online Library website: www.wileyonlinelibrary.com/journal/jan

\section{Reasons to publish your work in JAN:}

- High-impact forum: the world's most cited nursing journal, with an Impact Factor of 1.998 - ranked 12/114 in the 2016 ISI Journal Citation Reports $\odot$ (Nursing (Social Science)).

- Most read nursing journal in the world: over 3 million articles downloaded online per year and accessible in over 10,000 libraries worldwide (including over 3,500 in developing countries with free or low cost access).

- Fast and easy online submission: online submission at http://mc.manuscriptcentral.com/jan.

- Positive publishing experience: rapid double-blind peer review with constructive feedback.

- Rapid online publication in five weeks: average time from final manuscript arriving in production to online publication.

- Online Open: the option to pay to make your article freely and openly accessible to non-subscribers upon publication on Wiley Online Library, as well as the option to deposit the article in your own or your funding agency's preferred archive (e.g. PubMed). 